\title{
Ankle Ligaments on MRI: Appearance of Normal and Injured Ligaments
}

\author{
Prof. HananArafa, Dr. Merhan Ahmed Nasr and Mohamed Ibrahim Harraz
}

\begin{abstract} are analyzed.

\section{Introduction}

The ankle ligaments stabilize the bones of the hindfoot during motion, guide and constrain the complex movement of these bones with respect to the leg and midfoot bones, and transmit motion from one hindfoot bone to another. Bones and ligaments, together with the joint capsule, are functionally linked to form the hindfoot joint complex (Guillo et al., 2013). The most common clinical presentation of patients with
\end{abstract}

Ankle joint is a complex synovial joint affected in many traumatic and non traumatic conditions resulting in many problems. And ankle ligaments are encountered in multiple situations leading to be investigated well for detecting the accurate management. Inour study, we analyze the reliability and validity of magnetic resonance imaging (MRI) for the detection of ankle ligaments injuries. Thirty patients who are clinically suspected to have ligament injury are examined by MRI and results

ankle and foot pathology is pain and swelling followed by pain alone who attends the musculoskeletal clinic or orthopedic department. This leads to disability in performing regular normal activities (Baeet al., 2017).

MRI has revolutionized imaging of the entire musculoskeletal system. It plays a great role in ankle joint for depiction of soft tissue pathologies, such as ligament tears and chondral lesions (Roemer et al., 2014).

\section{Results}

Our study included 30 patients; 12 males and 18 females, with age ranges from 20 years to 51 years (mean age 35.5 years), suspecting to have ligamentous injury. All our patients complained from ankle pain associated with other symptoms like limitation of movement (in 17 cases), swelling (in 10 cases) and tingling and numbness (in 3 cases). History of trauma encountered in 18 patient and the others are non-traumatic. The patients were submitted to clinical examination and MRI examinations.

\begin{tabular}{|l|c|c|}
\hline \multicolumn{1}{|c|}{$\begin{array}{c}\text { The affected } \\
\text { ligament }\end{array}$} & Frequency & Percentage \\
\hline Anterior talo- fibular ligament & 9 & $30 \%$ \\
\hline Posterior talo-fibular ligament & 7 & $23.3 \%$ \\
\hline Calceneo-fibular ligament & 2 & $6.7 \%$ \\
\hline Deltoid ligament & 7 & $23.3 \%$ \\
\hline Anterior tibio-fibular ligament & 4 & $13.3 \%$ \\
\hline Posterior tibio-fibular ligament & 1 & $3.3 \%$ \\
\hline
\end{tabular}

Table (1): Frequency and percentage of ligamentousinjuries. 
This table shows that the anterior talo-fibular ligament is the most commonly affected ligament noted in 7 cases, the posterior talo-fibular ligament pathology was found in 6 cases, the calceneo-fibular ligament pathology was found in 2 cases, the deltoid ligament pathology was found in6 cases, the anterior tibio-fibular ligament pathology was found in 3 cases and the posterior tibio-fibular ligament pathology was found only in 1 case.

\begin{tabular}{|l|c|c|}
\hline $\begin{array}{l}\text { ligament } \\
\text { pathological } \\
\text { Entities }\end{array}$ & Frequency & Percentage(\%) \\
\hline ATFL sprain & 7 & 23.3 \\
\hline ATFL tear & $\mathbf{2}$ & 6.7 \\
\hline PTFL sprain & 5 & 16.7 \\
\hline PTFL tear & $\mathbf{2}$ & $\mathbf{6 . 7}$ \\
\hline CFL sprain & 1 & 3.3 \\
\hline CFL tear & $\mathbf{6}$ & $\mathbf{3 . 3}$ \\
\hline Deltoid sprain & 1 & 20 \\
\hline Deltoid tear & 3 & 3.3 \\
\hline A.Tib.F.L sprain & 1 & 10 \\
\hline A.Tib.F.L tear & 1 & 3.3 \\
\hline P.Tib.F.L sprain & 0 & 3.3 \\
\hline P.Tib.F.L tear & & 0 \\
\hline
\end{tabular}

Table (2): Frequency and percentage of different ligamentaous pathological entities:

This table shows that ATFL sprain was the most common pathology seen in 11 cases while ATFL tear was found in3cases. Regarding the PTFL pathological entities, PTFL sprain was the most common pathology seen in 8 cases while PTFL tear was found in 1case.Calceneo-fibular ligament tearwas found in 1 case.Deltoid ligament sprain was found in 3 cases while deltoid ligament tear was found only in1case. Anterior tibio-fibular ligament sprain was found in 1 case.Posteriortibiofibular ligamentsprain was found in 1 case.

\begin{tabular}{|c|c|c|}
\hline Type of impingement & Frequency & $\begin{array}{l}\text { Percentage to } \\
\text { total cases }\end{array}$ \\
\hline Posteriorimpingement & 6 & $20 \%$ \\
\hline Postero-medial impingement & 2 & $6.7 \%$ \\
\hline Anteriorimpingement & 1 & $3.3 \%$ \\
\hline
\end{tabular}

Table (3) : Frequency and percentage of impingement syndromes.

This table shows that the posterior impingement being the most common type (found in 6 cases), the postero-medial impingement was found in 2 cases and the anterior impingement was the least common type seen only 1 case. 


\begin{tabular}{|c|c|c|}
\hline The Etiology & Frequency & $\begin{array}{c}\text { Percentage to posterior } \\
\text { impingement cases }\end{array}$ \\
\hline Ostrigonumsyndrome & 2 & $33.3 \%$ \\
\hline Steida process & 4 & $66.7 \%$ \\
\hline
\end{tabular}

Table (4): Frequency and percentage of etiology of posterior impingement syndrome.

This table shows that posterior impingement caseswere due to prominent steida process (seen in 4 cases) and ostrigonum syndrome (seen in 2 cases).

\begin{tabular}{|c|c|c|}
\hline The lesion & Frequency & $\begin{array}{c}\text { Percentage to the } \\
\text { total cases }\end{array}$ \\
\hline Sinus Tarsi syndrome & 5 & $16.7 \%$ \\
\hline Bone Marrow edema & 17 & $56.7 \%$ \\
\hline Bursitis & 7 & $23.3 \%$ \\
\hline Joint Effusion & 16 & $53.3 \%$ \\
\hline Ganglion Cyst & 2 & $6.7 \%$ \\
\hline Haglund Syndrome & 1 & $3.3 \%$ \\
\hline
\end{tabular}

Table (5) : Frequency and percentage of other pathologies that could be also detected.

This table shows associated findings seen on MRI examination. Bone marrow edema was found to be the most common findings in our patient as it appeared in 17 cases followed by joint effusion which appeared in 16 patients. Bursitis was seen in 7 patients and sinus Tarsi syndrome was found in 5 patients. The least findings were ganglion cyst and haglund syndrome which found on 2 patients and a single patient respectively.

\section{Discussion}

The ankle is commonly affected in trauma as well as overuse disorders and inflammatory conditions. Various imaging techniques may be used to assess the ankle, including CT, MRI, and sonography. Imaging plays a crucial role in the evaluation of ankle tendons and ligaments (Alvarez et al., 2018).

MRI has been proven to provide excellent evaluation of ligaments and tendons around the ankle, with the ability to show various types of soft tissue and bony abnormalities (Alvarez et al., 2018).

Our study included twelve males patients represented $40 \%$ and eighteen female patients represented
$60 \%$, with their age ranged from 20 to 51 years (mean age was 35.5 years), the right side was affected in 17 patients $(57 \%)$ of all cases while the left side was affected in (43\%). This agreed with the study of (El-Liethy and Kamal,2016) which was performed on 35 patients with males represented $29 \%$ and females represented $71 \%$ with the age of cases ranged from 18-60 years (mean age was 37 years) with the right side was affected in $54.3 \%$ and the left side was affected in $45.7 \%$.The study of ElLiethy and Kamal, 2016reported that the

traumatic insult was the most common etiology of ligament injury 
noticed in $67 \%$ of their cases. This is agreed with our study in which most of our cases are presented by traumatic insult (noticed in 18/30 cases representing $60 \%$ ) while the other patients were non-traumatic.

Margetic et al., 2009reported that ankle pain is the most common presentation in patients with ligament injurynoticed in $66 \%$ of his cases. This is agreed with our study, in which all patients complained of ankle pain and associated with other symptoms, as limitation of movement which noticed in $17 / 30$ cases $(57 \%)$ swelling in $10 / 30$ patients $(33 \%)$ as well as tingling and numbness shown in $3 / 30$ cases $(10 \%)$.

Regarding ligament pathology, Grossterlindenet al., 2016stated that the anterior talo-fibular ligament was the most commonly affected ankle ligament injury in his study noticed in $34 \%$ of his cases. This is agreed with our study which revealed also that the anterior talo-fibular ligament being the most commonly affected ligament (noted in 9/30 cases) representing 30 $\%$ of all cases, this is followed by posterior talo-fibular ligament (noted in $7 / 30$ cases) representing $23.3 \%$.

Cremaetal. ,2018 stated that, visualization of an intact ATFL virtually excludes rupture of any of the lateral collateral ligaments and also stated that CFL and PTFL ruptures are not found in the presence of an intact ATFL. This is also agreed with our study which revealed that CFL tear and PTFL tear were always associated with ATFL tear.

Again Grossterlindenet al., 2016stated that the deltoid ligament is the strongest ankle ligament and least to be injured. He mentioned that $5.7 \%$ of his patients showed deltoid ligament tear. This is also noticed in our study, asdeltoid ligament tear was found in only $1 / 30$ case $(3.3 \%)$.

Cremaetal. ,2018stated in his study that ligament sprain was more common than ligament tear. $\mathrm{He}$ mentioned that $63 \%$ of all patients in his study showed different sprained ligaments. This In our study, ligament sprain was more common than ligament tear with the frequency of ATFL sprain was about $7 / 30$ cases $(23.3 \%)$ and the frequency of deltoid sprain was about $6 / 30$ cases $(20 \%)$.

Margetic et al., 2009 compared between ultrasound results and MRI results and stated that both ultrasound and MRI have the same ability to detect ATFL and CFL tears yielded a sensitivity of $100 \%$. This is agreed with our study, in which correlation between the ability of ultrasonography compared to MRI in detection of ATFL and CFL tears showed a sensitivity of $100 \%$.

Yasui et al., 2016 who stated that prominent steida process is the main osseous cause of the posterior ankle impingement. This is agreed with our study, in which posterior impingement was the most common impingement syndrome noticed in $6 / 30$ cases $(20 \%)$ with prominent steida process being the commonest etiological factor.

Yasui et al., 2016 who stated the most common associated finding with ligament injury was bone marrow edema. This is agree with our study which we encountered other associated pathologies noticed in the MRI examination and found thatbone marrow edema was seen in most cases $17 / 30$ cases $(56.7 \%)$. Other associated findings are synovial effusion which seen in $16 / 30$ cases $(53.3 \%)$, bursitis was seen in $7 / 30$ cases $(23.3 \%)$, sinus tarsi syndrome seen in 5/30 cases (16.7 $\%$ ), ganglion cyst was seen in $2 / 30$ cases $(6.7 \%)$ and haglund syndrome was seen in $1 / 30$ case $(3.3 \%)$.

\section{Conclusion}

MRI examination clearly
demonstrates the soft tissue
abnormalities and can also detect bony 
abnormalities like marrow edema, osteochondritisdessicans, bone tumors, impingement syndromes and entrapment neuropathy. The aim of this study is to evaluate the role of MRI in diagnosis of ligament injury. This study included thirty patients; 12 males and 18 females with age ranged from 20 to 51 years (mean age 35.5 years). All patients were subjected to clinical evaluation including full history taking and thorough clinical evaluation as well as radiological evaluation by MRI examination.

From our study, we conclude that MRI has a superior sensitivity and specificity in evaluation of ankle various ligaments injuries (including sprain, partial tear and complete tear) as well as impingement syndromes and bony abnormalities.

\section{References}

1. Alvarez, R., Marx, R., Mizel, M., Latta, L., \& Clifford, P. (2018). The Role of the Calcaneofibular Ligament in Chronic Ankle Pain Following Severe Ankle Sprains. Foot \& Ankle Orthopaedics, 3(3), 2473011418 S00143.

2. Bae, W. C., Ruangchaijatuporn, T., \& Chung, C. B. (2017). New techniques in MR imaging of the ankle and foot. Magnetic Resonance Imaging Clinics, 25(1), 211-225.

3. Crema, M. D., Krivokapic, B., Guermazi, A., Gravilovic, P., Popovic, N., D'Hooghe, P., \& Roemer, F. W. (2018). MRI of ankle sprain: the association between joint effusion and structural injury severity in a large cohort of athletes. European radiology, 1-9.

4. El-Liethy, N., \& Kamal, H. (2016). High resolution ultrasonography and magnetic resonance imaging in the evaluation of tendino-ligamentous injuries around ankle joint. The Egyptian Journal of Radiology and Nuclear Medicine, 47(2), 543-555.

5. Großterlinden, L. G., Hartel, M., Yamamura, J., Schoennagel, B., Bürger, N., Krause, M., ...\&Rupprecht, M. (2016). Isolated syndesmotic injuries in acute ankle sprains: diagnostic significance of clinical examination and MRI. Knee Surgery, Sports Traumatology, Arthroscopy, 24(4), 1180-1186.

6. Guillo, S., Bauer, T., Lee, J. W., Takao, M., Kong, S. W., Stone, J. W., ...\&Michels, F. (2013). Consensus in chronic ankle instability: aetiology, assessment, surgical indications and place for arthroscopy. Orthopaedics\& traumatology: surgery \& research, 99(8), S411-S419.

7. Margetic, P., Salaj, M., \&Lubina, I. Z. (2009). The value of ultrasound in acute ankle injury: comparison with MR. European Journal of Trauma and Emergency Surgery, 35(2), 141-146.

8. Roemer, F. W., Jomaah, N., Niu, J., Almusa, E., Roger, B., D’Hooghe, P., ...\&Guermazi, A. (2014). Ligamentous injuries and the risk of associated tissue damage in acute ankle sprains in athletes: a cross-sectional MRI study. The American journal of sports medicine, 42(7), 1549-1557.

9. Yasui, Y., Hannon, C. P., Hurley, E., \& Kennedy, J. G. (2016). Posterior ankle impingement syndrome: A systematic four-stage approach. World journal of orthopedics, 7(10), 657. 